\title{
Effect of residual vanadyl ions on the spectroscopic analysis of humic acids: a multivariate approach
}

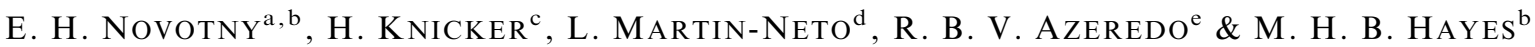 \\ ${ }^{\mathrm{a}}$ Embrapa Solos, Rua Jardim Botânico, 1024, CEP 22460-000, Rio de Janeiro, RJ, Brazil, ${ }^{\mathrm{b}}$ Chemical and Environmental Sciences, \\ University of Limerick, Limerick, Ireland, ${ }^{\mathrm{c}}$ Lehrstuhl für Bodenkunde, Technische Universität München, 85350 Freising-Weihenstephan, \\ Germany, ${ }^{\mathrm{d}}$ Embrapa Instrumentação Agropecuária, Rua XV de Novembro, 1452, CEP 13560-970, São Carlos, SP, Brazil, and ${ }^{\mathrm{e}}$ Instituto de \\ Química, Universidade Federal Fluminense, Outeiro de São João Batista, s/n ${ }^{\circ}$, Campus do Valonguinho, CEP 24020-150, Niterói, RJ, Brazil
}

\begin{abstract}
Summary
In a study of the vanadyl $\left(\mathrm{VO}^{2+}\right)$-humic acids system, the residual vanadyl ion suppressed fluorescence and specific electron paramagnetic resonance (EPR) and NMR signals. In the case of NMR, the proton rotating frame relaxation times $\left(\mathrm{T}_{1 \rho} \mathrm{H}\right)$ indicate that this suppression is due to an inefficient $\mathrm{H}-\mathrm{C}$ cross polarization, which is a consequence of a shortening of $\mathrm{T}_{1 \rho} \mathrm{H}$. Principal components analysis (PCA) facilitated the isolation of the effect of the $\mathrm{VO}^{2+}$ ion and indicated that the organic free radical signal was due to at least two paramagnetic centres and that the $\mathrm{VO}^{2+}$ ion preferentially suppressed the species whose electronic density is delocalized over $\mathrm{O}$ atoms (greater $g$-factor). Additionally, the newly obtained variables (principal components - PC) indicated that, as the result of the more intense tillage a relative increase occurred in the accumulation of: (i) recalcitrant structures; (ii) lignin and long-chain alkyl structures; and (iii) organic free radicals with smaller $g$-factors.
\end{abstract}

\section{Introduction}

Paramagnetic metal ions are frequently present in humic substances and can affect the spectroscopic results obtained, such as NMR (Preston et al., 1984; Preston, 1996; Smernik \& Oades, 1999, 2000; Novotny et al., 2006), fluorescence spectroscopy (Senesi, 1990a; Piana \& Zahir, 2000; Novotny et al., 2006), and EPR (Jezierski et al., 2000a,b; Novotny \& Martin-Neto, 2002; Novotny et al., 2006). Consequently, the interpretation of these spectroscopy results and their correlation with intrinsic characteristics of the samples, such as the degree of humification, can be erroneous. However, by way of these paramagnetic interferences it is possible to carry out studies to probe the binding sites and the functional groups involved (Mangrich \& Vugman, 1988; Smernik \& Oades, 1999; Novotny et al., 2006), and eventually to unveil more detailed structural information, such as distances apart of functional groups, and the conformations of humic substance (Novotny \& Martin-Neto, 2002; Schilling \& Cooper, 2004a).

The question arises as to whether or not the effects of paramagnetic ions can be isolated so that the spectroscopic data can be used to elucidate structures of humic substances. Multi-

Correspondence: E. H. Novotny. E-mail: etelvino@cnps.embrapa.br Received 15 February 2007; revised version accepted 26 September 2007 variate statistics, and especially PCA, provides a useful technique for such (Vandeginste et al., 1998; Novotny et al., 1999, 2007), as will be seen in this communication.

The vanadyl ion $\left(\mathrm{VO}^{2+}\right)$ has been used as a probe in spectroscopic studies (mainly EPR) of metal ion interactions with humic acids and other macromolecules (Mangrich \& Vugman, 1990; Novotny et al., 2006). Organic compounds that have nitrogen and oxygen ligands form very stable complexes with $\mathrm{VO}^{2+}$. However, in vanadyl-humic acid complexes the vanadyl ion is strongly immobilized by bonding to oxygen atoms only (McBride, 1978).

The environmental interest in vanadium has increased because of the reproductive toxicity of vanadium and because of the mutagenic and carcinogenic effects associated with the environmental pollution by this element, which is abundant in crude oils. Although it is found at small concentrations in water, rocks and soils, vanadium has been found to complex readily with humic substances (Mangrich \& Vugman, 1990; Senesi 1990b; Lu et al., 1998; Novotny et al., 2006).

The aims of this work are: (i) to isolate the effect of paramagnetic ions on the results of spectroscopic analysis (NMR, EPR and fluorescence) of humic acids extracted from an agricultural soil at an experimental station in Campinas-Brazil (Novotny et al., 2006); (ii) to assess the effect of cultivation on these humic acids; and (iii) to determine which functional groups are directly involved in the complexation of the metallic ions. 


\section{Materials and methods}

\section{Sample material and extraction of humic acids}

The humic acids were extracted from Typic Haplorthox soils, with clay contents between 500 and $650 \mathrm{~g} \mathrm{~kg}^{-1}$. The soils are from a long-term management systems experiment (15 years old) installed in Campinas, São Paulo State, Brazil $\left(47^{\circ} 05^{\prime} \mathrm{W}\right.$, $\left.22^{\circ} 54^{\prime} \mathrm{S}\right)$. The management systems were: conventional tillage; minimum tillage; and no-tillage. Crop rotation included maize (Zea mays) and soybean (Glycine max) in the summer and black oat (Avena strigosa) and Sunn hemp (Crotalaria juncea) in the winter. Samples were collected at depths of 0-5, 5-10, 10-20 and $20-30 \mathrm{~cm}$, giving a total of 12 samples.

The humic acids were extracted according to the method recommended by the 'International Humic Substances Society' (Swift, 1996).

\section{EPR measurements}

Measurements were carried out in duplicate at room temperature $(300 \mathrm{~K})$ using an X-Band Bruker EMX EPR spectrometer (Bruker BioSpin, Rheinstetten, Germany) with a modulation frequency of $100 \mathrm{kHz}$ in the magnetic field. The $g$-factor was measured against a standard of 2,2-diphenyl-1-picrylhydrazyl (DPPH) $(g=2.0036)$. For quantitative analysis, EPR quartz tubes $(2.5 \mathrm{~mm}$ I.D.) were filled to a height of $0.5 \mathrm{~cm}$ with humic acids, which corresponds to a sample mass of approximately $30 \mathrm{mg}$. To quantify the vanadyl ion content in arbitrary units, a ruby crystal was used as a secondary standard, according to Singer's method (see Singer, 1959; Novotny et al., 2006). The signal of the $\mathrm{VO}^{2+}$ ion was used because its EPR signal dominated those of the paramagnetic metal ions $\left(\mathrm{Fe}^{3+}\right.$ and $\mathrm{Cu}^{2+}$ ) detected in the samples (Novotny et al., 2006). The integrated signal areas were obtained by the approximation $\mathrm{Y}^{\prime} \Delta \mathrm{H}^{2}$ (Poole, 1983), where $\mathrm{Y}^{\prime}$ is the EPR derivative signal amplitude and $\Delta \mathrm{H}$ is the peak-to-peak line width. The sixth perpendicular resonance line of the $\mathrm{VO}^{2+}$ ion $\left(\mathrm{M}_{\mathrm{I}}=-3 / 2\right)$ was selected because this was intense and relatively isolated from any other resonance lines in the spectrum. By comparing the areas of the EPR $\mathrm{VO}^{2+}$ signals of the samples with the signal areas of standard frozen $\mathrm{VO}^{2+}$ solutions, measured at the same experimental conditions, it was estimated that the $\mathrm{VO}^{2+}$ ion concentration in the samples was in the range of $20-60 \mu \mathrm{g} \mathrm{g}^{-1}$.

\section{Solid-state ${ }^{13}$ C NMR spectroscopy}

Solid-state ${ }^{13} \mathrm{C}$ NMR data were obtained at a resonance frequency of $100.6 \mathrm{MHz}$ using a Varian Inova 400 spectrometer (Varian, Palo Alto, CA, USA). The humic acids samples were placed in a $5-\mathrm{mm}$ diameter cylindrical zirconium rotor with a Kel-F end-cap and spun at $8 \mathrm{kHz}$ in a Doty Scientific MAS probe (Doty Scientific, Columbia, SC, USA). Free induction decay data were acquired with a $40 \mathrm{kHz}$ sweep width, and 512 data points were collected over a $12.8 \mathrm{~ms}$ acquisition time. The spectra were acquired with a variable amplitude cross polarization/magic angle spinning VACP/MAS pulse sequence, consisting of a $4 \mu$ s preparation ${ }^{1} \mathrm{H}$ pulse and a contact time of $1 \mathrm{~ms}$. The pulse delay of $500 \mathrm{~ms}$ was more than five times longer than the longest ${ }^{1} \mathrm{H}$-spin relaxation time, determined with inversion-recovery experiments. To avoid Hartmann-Hahn mismatches due to interfering frequencies at high spinning speeds (Peersen et al., 1993), a ramped ${ }^{1} \mathrm{H}$-pulse varying from 110 to $60 \%$ of the power level was used. This power range was chosen from pre-experiments where the radio frequency power level was varied until the relative intensities of signals, suppressed with conventional CP/MAS (for example methyl, methoxyl, aryl and carboxyl), were constant. A total of 9600 transients were collected.

Additionally, to verify the mechanism involved in the suppression effect of the vanadyl ion in the NMR signal intensity, the proton rotating frame relaxation times $\left(T_{1 \rho} \mathrm{H}\right)$ were determined in six selected samples by a Variable Spin Lock experiment (Smernik et al., 2002). These measurements were carried out using a VACP/MAS pulse sequence in a Bruker DSX 200 NMR spectrometer (Bruker Biospin, Rheinstetten, Germany) $\left({ }^{13} \mathrm{C}\right.$-resonance frequency: $\left.50.32 \mathrm{MHz}\right)$ at a spinning speed of $6.8 \mathrm{kHz}$, a contact time of $0.5 \mathrm{~ms}$ with an array of 34 spin-lock times and a pulse delay of $300 \mathrm{~ms}$. This shorter contact time was used to detect better the rapidly relaxing components (Smernik et al., 2002). The area under the various chemical shift regions - alkyl (0-45 p.p.m.), methoxyl, N-alkyl (45-59 p.p.m.), O-alkyl (59-91 p.p.m.), di-O-alkyl (91-109 p.p.m.), aryl (109-143 p.p.m.), O-aryl (143-156 p.p.m.), and carboxyl, amide (156-186 p.p.m.) - were used for the fitting. Single and two component models were fitted, and the best model was determined according to the $F$-test (Smernik et al., 2002).

\section{Fluorescence spectroscopy}

The fluorescence spectra were obtained using a PerkinElmer LS50B luminescence spectrometer (PerkinElmer, Waltham, MA, USA). The humic acids were solubilized in $0.05 \mathrm{~mol}$ litre $^{-1}$ $\mathrm{NaHCO}_{3}(\mathrm{pH}=8.5)$ at a concentration of $50 \mathrm{mg}$ litre ${ }^{-1}$. Emission spectra were recorded from 300 to $650 \mathrm{~nm}$ and 470 to $650 \mathrm{~nm}$ at constant excitation wavelengths of 243 and 455 $\mathrm{nm}$, respectively. Excitation spectra were obtained by scanning from 220 to $480 \mathrm{~nm}$ and measuring the radiation emitted at $500 \mathrm{~nm}$. Excitation and emission slits were set at $10 \mathrm{~nm}$ bandwidth and the sweep resolution at $0.5 \mathrm{~nm}$, and a scanning speed of $20 \mathrm{~nm} \mathrm{~s}^{-1}$ was used for both monochromators.

\section{PCA analysis}

A window in the range of 270 at -10 p.p.m. (290 experimental points) was selected for the NMR data, and 100 points (variables) were used for EPR and fluorescence spectroscopy. The spectral data (NMR, EPR and fluorescence) of the 12 samples 
were centred by subtracting the average value of the samples for each data point. That means that the results can be interpreted in terms of deviations from the average. The PCA was carried out using MATLAB (The MathWorks, Natick, MA, USA) and The Unscrambler (CAMO Software AS, Oslo, Norway) software. In all cases, two components were extracted, capturing at least $90 \%$ of the total variance. The model validation was carried out using different methods: full cross-validation, and segmented cross-validation with two and three samples per segment picked at random. The difference in the variance between the calibration and validation models was less than $5 \%$.

\section{Results and discussion}

The EPR spectra showed the typical signal of: dipolar interactions between neighbouring $\mathrm{Fe}^{3+}$ ions; the signals of organic free radicals; $\mathrm{Fe}^{3+}$ in rhombic symmetry sites; $\mathrm{Cu}^{2+}$ in axial symmetry; and $\mathrm{VO}^{2+}$ in an inner sphere complex with humic acids in a ligand environment consisting mainly of oxygen donors on the equatorial plane of the $\mathrm{VO}^{2+}$ complex. Details about EPR analysis and interpretation can be found in Novotny et al. (2006).

Regarding $\mathrm{T}_{1 \rho} \mathrm{H}$, the fitting of spin-lock data and the $F$-test indicate at least two components, one slow and one rapidly relaxing (Table 1). The O-C groups, from carboxyl and carbohydrates (O-alkyl and di-O-alkyl), show the shorter $\mathrm{T}_{1 \rho} \mathrm{H}$ values for the rapidly relaxing components, and the proportion of these components correlates with the vanadyl ion contents ( $r=0.99,0.95$ and 0.97 for carboxyl, di-O-alkyl and O-alkyl, respectively). Correlation analyses, carried out on earlier work (Novotny et al., 2006), have indicated that vanadyl ions have a strong interaction with the O-C groups from carboxyl and carbohydrates (O-alkyl and di-O-alkyl). The present $\mathrm{T}_{1 \rho} \mathrm{H}$ measurements support the view that this suppression is possibly due to a shortening of $\mathrm{T}_{1 \rho} \mathrm{H}$ by dipolar interaction. However, the contribution of other mechanisms, such as paramagnetic shift and/or broadening of the resonances (Günther, 1995; Wickramasinghe \& Ishii, 2006) cannot be ruled out.

Table 1 Proton rotating frame relaxation times $\left(T_{1 \rho} H\right)$, average of six selected samples, with standard errors

\begin{tabular}{lcc}
\hline & \multicolumn{2}{c}{$\mathrm{T}_{1 \rho} \mathrm{H} / \mathrm{ms}$} \\
\cline { 2 - 3 } Functional group & $\begin{array}{c}\text { Slowly relaxing } \\
\text { component }\end{array}$ & $\begin{array}{c}\text { Rapidly relaxing } \\
\text { components }\end{array}$ \\
\hline Carboxyl, amide (156-186 p.p.m.) & $4.49 \pm 0.18$ & $0.47 \pm 0.02$ \\
O-aryl (143-156 p.p.m.) & $4.82 \pm 0.24$ & $0.60 \pm 0.02$ \\
Aryl (109-143 p.p.m.) & $4.89 \pm 0.21$ & $0.59 \pm 0.04$ \\
di-O-alkyl (91-109 p.p.m.) & $4.49 \pm 0.30$ & $0.46 \pm 0.02$ \\
O-alkyl (59-91 p.p.m.) & $4.07 \pm 0.21$ & $0.40 \pm 0.03$ \\
Methoxyl, N-alkyl (45-59 p.p.m.) & $4.57 \pm 0.28$ & $0.61 \pm 0.03$ \\
Alkyl (0-45 p.p.m.) & $4.58 \pm 0.31$ & $0.62 \pm 0.02$ \\
\hline
\end{tabular}

The vanadyl ion was present in the range of $20-60 \mu \mathrm{g} \mathrm{g}^{-1}$ and it may be questioned as to how such a small content can have detectable effects. Additionally, these effects on the NMR signal intensity were not stoichiometric. That could be explained by considering: that each of the $\mathrm{VO}^{2+}$ coordination bonds could involve dipolar interaction $(<1 \mathrm{~nm})$ in altered (e.g. the formation of uronic acids) or fragmented cellulose structures; $\mathrm{VO}^{2+}$ coordination would occur in hydrophilic domains, affecting other surrounding groups; based in the $\mathrm{T}_{1 \rho} \mathrm{H}$ and proton spin diffusion values the selective signal loss, caused by the paramagnetic ion, can affect the groups in the range 2-30 nm (Zumbulyadis, 1983; Schilling \& Cooper, 2004b); and, the metal coordination could be a cause of a steric rearrangement of the humic acids (Schilling \& Cooper, 2004a), and other hydrophilic groups would be moved closer to the binding sites. Additionally, the contents of other paramagnetic ions can be correlated with the $\mathrm{VO}^{2+}$ content. In this way, the $\mathrm{VO}^{2+}$ ion could be regarded as a probe to indicate the nature of the binding sites. It could be interpreted as a sampling of the ion's population, and a greater content of $\mathrm{VO}^{2+}$ ions would indicate a greater content of other paramagnetic ions in similar binding sites. However, EPR was not able to provide a better speciation of these other detectable paramagnetic ions, as was the case for $\mathrm{VO}^{2+}$, because these ions exist also in other forms (e.g. in clusters) (Novotny et al., 2006).

Regarding the PCA, the first principal component (PC1), from the ${ }^{13} \mathrm{C}$ VACP MAS NMR spectra, captured $67 \%$ of the total variance. Its spectral regions with greater loadings were those associated with lignin (aryl, O-aryl and methoxyl) and C-alkyl (Figure 1a). The PC2 (25\% of the total variance) presents the greatest loadings in the spectral region of groups possibly coordinated to $\mathrm{VO}^{2+}$, such as carboxyl, O-alkyl and di-O-alkyl (Figure 1b). That is confirmed by the strong correlation obtained between the scores of this $\mathrm{PC}$ and the $\mathrm{VO}^{2+}$ content (Table 2). Other regions with positive loadings were from $\mathrm{CH}_{3}$ groups $\left(\sim 19\right.$ p.p.m.), rigid $\left(\mathrm{CH}_{2}\right)_{\mathrm{n}}$ groups (peak at 32.8 p.p.m.) and aryl $\mathrm{C}(\sim 128$ p.p.m. $)$, indicating spatial proximity of these groups to the $\mathrm{VO}^{2+}$ binding sites or, in the case of the alkyl region, that some of the hydroxyl and carboxyl groups involved in the $\mathrm{VO}^{2+}$ complexation are from compounds like alkanoic acids and alkanols.

Similar results were reported by Schilling \& Cooper (2004a) when studying $\mathrm{Cu}$ complexation by humic acids. These authors suggested the spatial proximity of aryl and alkyl groups to the binding sites, or that the complexation induces a change in the conformation of the organic structure (pseudochelation).

Because the NMR spectra were normalized (unitary area) before the PCA, to avoid interference from the amount of sample used and pulse imperfections, the decrease in the signal intensity of some groups corresponds to a relative increase in the intensity of the other non-affected $\mathrm{C}$ groups. In this way the area sums result in the unitary value. That could explain the negative loadings of $\mathrm{PC} 2$ in the regions attributed to chemical groups not affected by $\mathrm{VO}^{2+}$, that is mainly lignin signals (Figure 1b). 
(a)

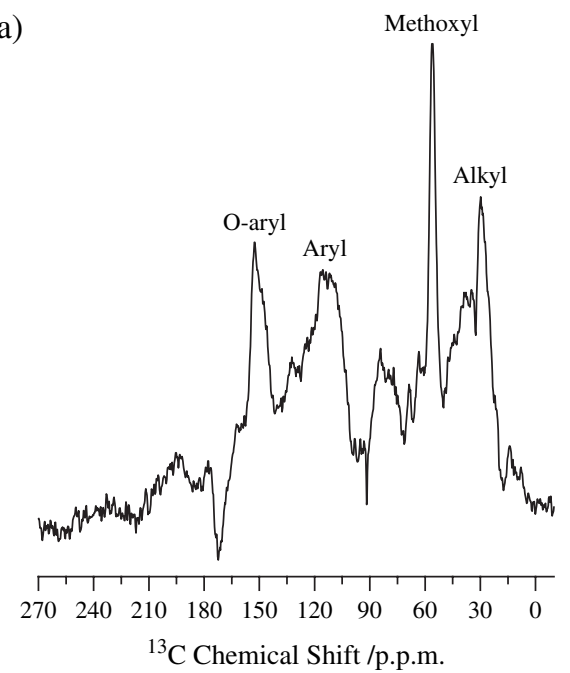

(b)

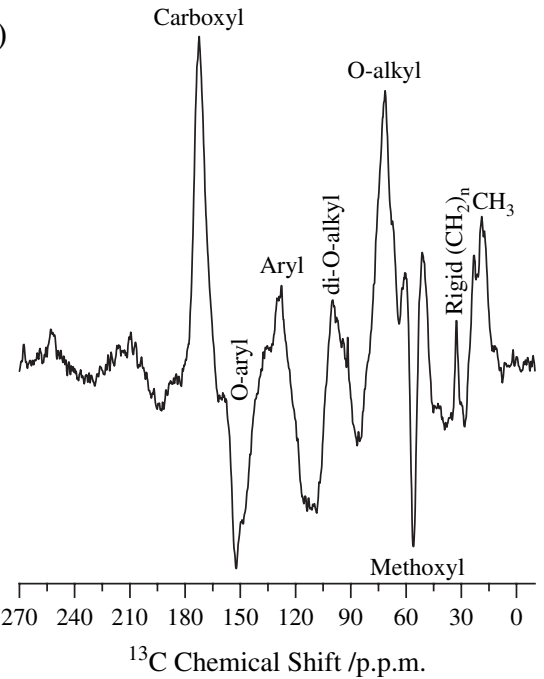

Figure 1 Loadings of the principal component (PC) extracted from the ${ }^{13} \mathrm{C}$ VACP MAS NMR spectra: (a) PC1 (66.85\% of the total variance); (b) PC2 $(24.73 \%$ of the total variance).

The scores from PC1 clearly differentiate the humic acid samples according to the distinct treatments (Figure 2). The greatest score was associated with the upper superficial layer $(0-5 \mathrm{~cm})$, where tillage was most intense, followed, proportionally, by the 5-10 cm layer. Hence, in areas of intense cultivation there is an apparent accumulation of structures associated with lignin (151, 114 and 56 p.p.m.) and alkyl-C, such as crystalline and non-crystalline poly(methylene) (33 and 30 p.p.m., respectively) and methyl groups ( $0-27$ p.p.m.), indicating that such structures have a greater recalcitrance under these conditions.

The score values of $\mathrm{PC} 1$ were similar for the different cultivation systems for the humic acids isolated at depths of 10-20 and $20-30 \mathrm{~cm}$, and the values decreased at lower depths, showing that the effects of tillage on the humic acids are limited to the upper layers. It further reveals that the contribution of structures associated with lignin is small in humic acids from the $20-30 \mathrm{~cm}$ layer.

The two PC extracted from the EPR data allow us to conclude that the signal of organic free radicals in humic acids is due at least to two paramagnetic centres (Figure 3a), as $\mathrm{VO}^{2+}$ suppressed preferably the low field signal $(g=2.0042)$, repre-

Table 2 Captured variance and correlation with the $\mathrm{VO}^{2+}$ content of the $\mathrm{PC}$ attributed to the effect of this ion

\begin{tabular}{llcc}
\hline Spectroscopy & & $\begin{array}{c}\text { Captured } \\
\text { variance } / \%\end{array}$ & $\begin{array}{c}\text { Correlation } \\
\text { with } \mathrm{VO}^{2+} \text { ion }\end{array}$ \\
\hline Fluorescence & Emission $\left(\lambda_{\mathrm{ex}}=243 \mathrm{~nm}\right)$ & 99.98 & -0.92 \\
& Emission $\left(\lambda_{\mathrm{ex}}=455 \mathrm{~nm}\right)$ & 99.81 & -0.93 \\
& Excitation $\left(\lambda_{\mathrm{em}}=500 \mathrm{~nm}\right)$ & 97.36 & -0.95 \\
& ${ }^{13} \mathrm{C}-\mathrm{RMN}$ & 24.73 & -0.95 \\
& Organic free radicals & 64.61 & -0.88 \\
\hline
\end{tabular}

sented by PC1 (Table 2). This can be interpreted as evidence for strong interaction between $\mathrm{VO}^{2+}$ and the organic free radicals whose resonance signal give a greater $g$-factor. This can be explained by the nature of these radicals, because an increase in the electron density of an unpaired electron over oxygen atoms gives rise to an increase in the $g$-factor in organic free radicals (Parish, 1990).

The loadings of PC2 (25\% of the total variance) had a $g$-factor of 2.0029, indicating a free radical centre in which the unpaired electron is delocalised over the carbon backbone, probably in aromatic condensed structures, and its scores confirmed the trend for humification (data not shown) as demonstrated by the scores from the ${ }^{13} \mathrm{C}$ NMR.

In the case of the fluorescence spectra, $\mathrm{PC} 1$ captured at least $97 \%$ of the total variance in all acquisition modes, and the scores of this PC had a strong correlation with the $\mathrm{VO}^{2+}$ contents.

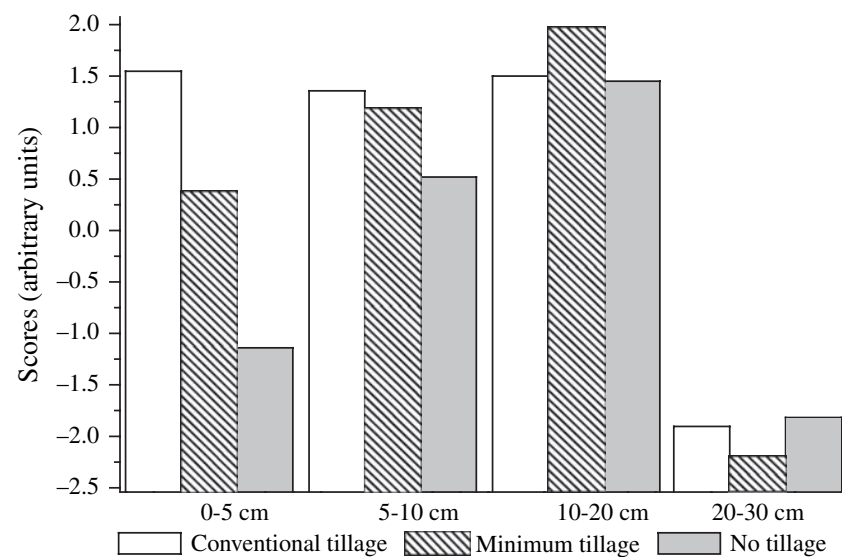

Figure 2 Scores of the PC1 $(66.85 \%$ of the total variance) extracted from the ${ }^{13} \mathrm{C}$ VACP MAS NMR spectra. 
(a)

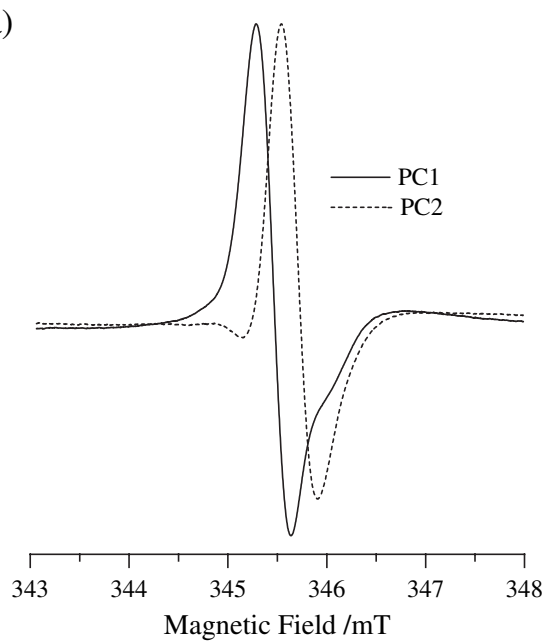

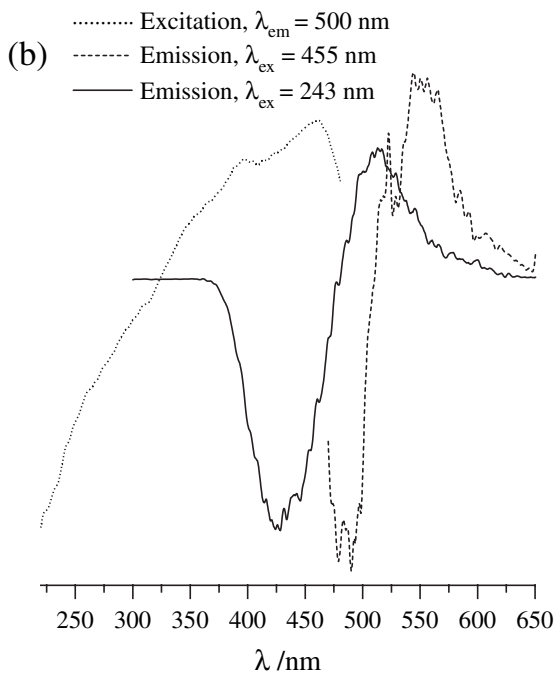

Figure 3 Loadings of: (a) two PC from EPR data; (b) PC2 of fluorescence data. Emission with excitation at $243 \mathrm{~nm}(0.16 \%$ of the total variance); emission with excitation at $455 \mathrm{~nm}(0.02 \%$ of the total variance); emission with excitation at $500 \mathrm{~nm}(2.57 \%$ of the total variance).

Practically all the observed variance was due to the effect of this ion (Table 2).

The loadings of PC2 in the fluorescence data present a red shift, e.g. positive loadings to longer wavelengths and negative loadings to shorter wavelengths (Figure $3 b$ ). This red shift is a typical characteristic of humic substances with large degrees of humification (Senesi, 1990a; Piana \& Zahir, 2000). Consequently, these PC might be associated with the degree of humification; the greater the scores the greater the humification.

The scores of PC2 extracted from excitation spectra with emission at $500 \mathrm{~nm}$ indicated that increasing the tillage intensity generated more humified humic acids in the $0-5 \mathrm{~cm}$ layer. Humic acid samples from the $20-30 \mathrm{~cm}$ layer presented a lesser degree of humification (data not shown), in accordance with the results of the PCA from NMR and EPR data.

\section{Conclusions}

The $\mathrm{VO}^{2+}$ ion affected the spectroscopy results obtained by different techniques (EPR, NMR, and fluorescence) in such a way that a straightforward interpretation of the results has to be made with care because a considerable part of the observed variability did not derive from intrinsic characteristics of the humic acid samples, such as the degree of humification. As a consequence, multivariate techniques were applied to isolate the $\mathrm{VO}^{2+}$ ion effect and to obtain new independent variables from it. These new variables were used to estimate the degree of humification and to evaluate the effects of cultivation on humic acids.

Where the most intense soil cultivation was practised, more humified humic acids were obtained, mainly in the upper layers (down to $10 \mathrm{~cm}$ ), as indicated by the fluorescence and EPR data.
Greater contents, in the humic acids, of recalcitrant structures associated with lignin and long-chain alkyl-C were related to greater humification. We found also that the organic free radicals of the humic acids were attributable to two distinct paramagnetic centres. The $\mathrm{VO}^{2+}$ ion suppressed preferentially the signal with the greater $g$-factor, attributed to organic free radicals with a greater electron density in which the unpaired electron is located over oxygen atoms compared with the unaffected signal whose unpaired electron is delocalised, probably over conjugated $\mathrm{C}$ atoms.

\section{Acknowledgements}

The authors are grateful to the Fundação de Amparo à Pesquisa do Estado de São Paulo (FAPESP) and to the Irish Research Council for Science, Engineering and Technology (IRCSET) for post-doctoral support. Thanks are due to Dr Antonio Riul Jr for assistance with proof reading of the text.

\section{References}

Günther, H. 1995. NMR Spectroscopy - Basic Principles, Concepts, and Applications in Chemistry, 2nd edn. Wiley, New York.

Jezierski, A., Czechowski, F., Jerzykiewicz, M., Chen, Y. \& Drozd, J. 2000a. Electron paramagnetic resonance (EPR) studies on stable and transient radicals in humic acids from compost, soil, peat and brown coal. Spectrochimica Acta Part A - Molecular and Biomolecular Spectroscopy, 56, 379-385.

Jezierski, S., Czechowski, F., Jerzykiewicz, M. \& Drozd, J. 2000 b. EPR investigations of structure of humic acids from compost, soil, peat and soft brown coal upon oxidation and metal uptake. Applied Magnetic Resonance, 18, 127-136. 
Lu, X.Q., Johnson, W.D. \& Hook, J. 1998. Reaction of vanadate with aquatic humic substances: an ESR and V-51 NMR study. Environmental Science \& Technology, 32, 2257-2263.

Mangrich, A.S. \& Vugman, N.V. 1988. Bonding parameters of vanadyl ion in humic acid from the Jucu river estuarine region, Brazil. Science of the Total Environment, 75, 235-241.

Mangrich, A.S. \& Vugman, N.V. 1990. Vanadyl ion $\left(\mathrm{VO}^{2+}\right)$ as a spectroscopic probe of metal binding to nitrohumic acid. Fuel, 69, 925-927.

McBride, M.B. 1978. Transition metal binding in humic acid: an ESR study. Soil Science, 126, 200-209.

Novotny, E.H. \& Martin-Neto, L. 2002. Effects of humidity and metal ions on the free radicals analysis of peat humus. Geoderma, 106, 305-317.

Novotny, E.H., Blum, W.E.H., Gerzabek, M.H. \& Mangrich, A.S. 1999. Soil management system effects on size fractionated humic substances. Geoderma, 92, 87-109.

Novotny, E.H., Knicker, H., Colnago, L.A. \& Martin-Neto, L. 2006. Effect of residual vanadyl on the spectroscopic analysis of humic acids. Organic Geochemistry, 37, 1562-1572.

Novotny, E.H., deAzevedo, E.R., Bonagamba, T.J., Cunha, T.J.F., Madari, B.E., Benites, V.M. et al. 2007. Studies of the compositions of humic acids from Amazonian dark earth soils. Environmental Science \& Technology, 41, 400-405.

Parish, R.V. 1990. NMR, NQR, EPR and Mössbauer Spectroscopy in Inorganic Chemistry. Elis Horwood, London.

Peersen, O.B., Wu, X.L., Kustanovich, I. \& Smith, S.O. 1993. Variable-amplitude cross-polarization MAS NMR. Journal of Magnetic Resonance Series A, 104, 334-339.

Piana, M.J. \& Zahir, K.O. 2000. Investigation of metal ions binding of humic substances using fluorescence emission and synchronousscan spectroscopy. Journal of Environmental Science and Health Part B-Pesticides Food Contaminants and Agricultural Wastes, 35, 87-102.

Poole, C.F. 1983. Electron Spin Resonance: A Comprehensive Treatise on Experimental Techniques, 2nd edn. Wiley, New York.

Preston, C.M. 1996. Applications of NMR to soil organic matter analysis: history and prospects. Soil Science, 161, 144-166.

Preston, C.M., Dudley, R.L., Fyfe, C.A. \& Mathur, S.P. 1984. Effects of variations in contact times and copper contents in a C-13 CPMAS NMR-study of samples of 4 organic soils. Geoderma, 33, 245-253.
Schilling, M. \& Cooper, W.T. 2004a. Identification of copper binding sites in soil organic matter through chemical modifications and ${ }^{13} \mathrm{C}$ CP-MAS NMR spectroscopy. Environmental Science \& Technology, 38, 5059-5063.

Schilling, M. \& Cooper, W.T. 2004b. Effects of chemical treatments on the quality and quantitative reliability of solid-state ${ }^{13} \mathrm{C} N M R$ spectroscopy of mineral soils. Analytica Chimica Acta, 508, 207-216.

Senesi, N. 1990a. Molecular and quantitative aspects of the chemistry of fulvic-acid and its interactions with metal-ions and organicchemicals. 2. The fluorescence spectroscopy approach. Analytica Chimica Acta, 232, 77-106.

Senesi, N. 1990b. Application of Electron Spin Resonance (ESR) Spectroscopy in Soil Chemistry. Springer, New York.

Singer, L.S. 1959. Synthetic ruby as a secondary standard for the measurement of intensities in electron paramagnetic resonance. Journal of Applied Physics, 30, 1463-1464.

Smernik, R.J. \& Oades, J.M. 1999. Effects of added paramagnetic ions on the C-13 CP MAS NMR spectrum of a de-ashed soil. Geoderma, 89, 219-248.

Smernik, R.J. \& Oades, J.M. 2000. Effect of paramagnetic cations on solid state C-13 nuclear magnetic resonance spectra of natural organic materials. Communications in Soil Science and Plant Analysis, 31, 3011-3026.

Smernik, R.J., Baldock, J.A., Oades, J.M. \& Whittaker, A.K. 2002. Determination of $\mathrm{T}_{1 \rho} \mathrm{H}$ relaxation rates in charred and uncharred wood and consequences for NMR quantitation. Solid State Nuclear Magnetic Resonance, 22, 50-70.

Swift, R.S. 1996. Organic matter characterization. In: Methods of Soil Analysis. Part 3. Chemical Methods (ed. D. L. Sparks), pp. 10181020. Soil Science Society of America, Madison, WI.

Vandeginste, B.G.M., Massart, D.L., Buydens, L.M.C., De Jong, S., Lewi, P.J. \& Smeyers-Verbeke, J. 1998. Data Handling in Science and Technology: Handbook of Chemometrics and Qualimetrics. Elsevier Science, Amsterdam.

Wickramasinghe, N.P. \& Ishii, Y. 2006. Sensitivity enhancement, assignment, and distance measurement in ${ }^{13} \mathrm{C}$ solid-state NMR spectroscopy for paramagnetic systems under fast magic angle spinning. Journal of Magnetic Resonance, 181, 233-243.

Zumbulyadis, N. 1983. Selective carbon excitation and the detection of spatial heterogeneity in cross-polarization magic-angle-spinning NMR. Journal of Magnetic Resonance, 53, 486-494. 